\title{
Autolysis of a Division Mutant of Escherichia coli
}

\author{
By DORIS KARIBIAN, ${ }^{1}$ G. PELLON ${ }^{2}$ AND J. STARKA ${ }^{1 *}$ \\ ${ }^{1}$ Laboratoire de Physiologie Microbienne, Faculté des Sciences de Luminy, Université \\ d'Aix-Marseille 2, 13009 Marseille, France \\ ${ }^{2}$ Laboratoire de Biochimie Microbienne, Université de Lyon 1, 69100 Villeurbanne, France
}

(Received 22 December 1980; revised 23 March 1981)

\begin{abstract}
The pleiotropic character of the envC chain-forming mutant of Escherichia coli was found to include leakage of periplasmic enzymes and an abnormal tendency to autolyse. Washed suspensions of envC cells released murein fragments into the supernatant, and cell extracts from the mutant were richer than those of the wild type in exo- $\beta$ - $N$-acetylglucosaminidase ( $187 \%$ of the wild-type value) and in soluble endopeptidase $(256 \%)$ activities, but $\mathrm{N}$-acetylmuramoylamidase, D,D-carboxypeptidase, L,D-carboxypeptidase and transglycosylase were not markedly different. When envC cells were grown in medium containing $0.58 \mathrm{M}$-sucrose, the chains broke up into rods, the L,D-carboxypeptidase activity increased about sixfold and D,D-carboxypeptidase 1B about twofold. It is suggested that L,Dcarboxypeptidase is involved in septum splitting. The results suggest that the triggering of autolysis in $E$. coli env $C$ depends on the alteration of envelope constituents rather than on an enhanced activity of murein hydrolases.
\end{abstract}

\section{INTRODUCTION}

Escherichia coli is very resistant to peptidoglycan breakdown by endogenous hydrolases and reports of autolysis of this species are rare. Cell suspensions of $E$. coli in growth medium or in buffer are fairly stable (Hartmann et al., 1974), but chemical treatment and osmotic shock, individually (Leduc \& van Heijenoort, 1980) or combined with nutritional shift (Mitchell \& Moyle, 1956), can induce rapid autolysis. Autolytic enzymes are believed to participate in wall growth, division and shape maintenance of growing cells but their true physiological role is controversial (Fan, 1970; Ghuysen \& Shockman, 1973; Fein \& Rogers, 1976; Hinks et al., $1978 a, b$ ).

We have reported earlier that growing cultures of the env $C$ mutant of $E$. coli $\mathrm{K} 12$ contain a significant fraction of cells undergoing autolysis (Rodolakis et al., 1973). The mutant grows in the form of long chains and electron microscopy shows that septum formation is often incomplete and irregular. The envC mutant is hypersensitive to various antibiotics, dyes and detergents (Starka et al., 1974) and leaks the periplasmic enzymes alkaline phosphatase and ribonuclease during growth (Starkova et al., 1978). These varied properties have prompted us to examine the autolytic behaviour of the envC mutant and the activity of several of its murein hydrolases.

\section{METHODS}

Bacterial strains, culture conditions and preparation of extracts. Escherichia coli K 12 strain P678 and its isogenic, chain-forming envC derivative were used. Their genotypes and culture conditions were as previously described (Michel et al., 1977). Cells were harvested in mid-exponential phase at an $A_{450}$ of 0.5-0.6 (Bausch and Lomb Spectronic 21 instrument), centrifuged at $3000 \mathrm{~g}$ for $15 \mathrm{~min}$ at $4{ }^{\circ} \mathrm{C}$, resuspended in $5 \mathrm{ml}$ per $\mathrm{g}$ wet wt of 
bacteria of cold $20 \mathrm{~mm}$-potassium phosphate buffer $\mathrm{pH} 7.0$ or $30 \mathrm{~mm}$-Tris/ $\mathrm{HCl} \mathrm{pH} 7.3$, broken in a French press (Aminco) at 4-5 ton in ${ }^{-2}(62-77 \mathrm{MPa})$, and centrifuged at $3000 \mathrm{~g}$ for $10 \mathrm{~min}$; the supernatant was recentrifuged at $100000 \mathrm{~g}$ for $60 \mathrm{~min}$ at $4{ }^{\circ} \mathrm{C}$. The resulting supernatant is referred to as the soluble fraction, and the pellet which was taken up in 1-2 $\mathrm{ml}$ of cold phosphate buffer or Tris/ $\mathrm{HCl}$ buffer as the envelope fraction. Extracts were stored at $-18^{\circ} \mathrm{C}$.

To measure autolytic activity in growing cells, we used a medium containing $100 \mathrm{~mm}$-Tris/ $\mathrm{HCl} \mathrm{pH} 7 \cdot 4$, $0.2 \mathrm{~mm}-\mathrm{K}_{2} \mathrm{HPO}_{4}, 0.1 \%(\mathrm{w} / \mathrm{v}) \mathrm{NH}_{4} \mathrm{Cl}, 1 \mathrm{~mm}-\mathrm{MgSO}_{4}, 0.5 \%(\mathrm{w} / \mathrm{v}) \mathrm{NaCl}$ and $0.2 \%(\mathrm{w} / \mathrm{v})$ glucose, supplemented with threonine $\left(100 \mu \mathrm{g} \mathrm{ml}^{-1}\right)$, leucine $\left(20 \mu \mathrm{g} \mathrm{ml}^{-1}\right)$, thiamin $\left(1 \mu \mathrm{g} \mathrm{ml}^{-1}\right)$, and Casamino acids $\left(100 \mu \mathrm{g} \mathrm{ml}^{-1}\right)$. $\beta$-Galactosidase was induced by adding $0.5 \mathrm{~mm}$-isopropyl- $\beta$-D-thiogalactopyranoside (IPTG) about $1 \mathrm{~h}$ before harvesting.

Substrates. $\quad\left[{ }^{14} \mathrm{C}\right]$ Diaminopimelate-labelled sacculi and $\left[{ }^{3} \mathrm{H}\right]$ diaminopimelate-labelled bis(disaccharidetetrapeptide) were prepared from cell walls of $E$. coli W7 lys $A$ dap by methods already described (Primosigh et al., 1961; Hartmann, 1973; Hartmann et al., 1974). $N$-Acetylmuramoyl-L-alanyl- $\gamma$-D-glutamyl-L- $\left|{ }^{3} \mathrm{H}\right|$ meso- $^{-}$ diaminopimelic acid was kindly provided by J. van Heijenoort.

UDP- $N$-acetylmuramoyl-L-alanyl- $\gamma$-D-glutamyl-(L)-meso-diaminopimelic acid (UDP-MurNAc-tripeptide) was extracted from Bacillus cereus $\mathrm{T}$ (received from J. van Heijenoort) by a modification of the method described by Lugtenberg et al. (1972); cells grown in complete medium were harvested in exponential phase and incubated for $90 \mathrm{~min}$ in half the volume of synthetic medium containing $150 \mu \mathrm{g}$ meso-diaminopimelic acid $\mathrm{ml}^{-1}$ and $100 \mu \mathrm{g}$ D-cycloserine $\mathrm{ml}^{-1}$ (Strominger et al., 1959). The extraction and purification of the precursor were performed without modification.

UDP- $N$-acetylmuramoyl-L-alanyl- $\gamma$ - -glutamyl-(L)-meso-2,6-diaminopimelyl-D- $\left[1-{ }^{14} \mathrm{C}\right]$ alanyl-D- $\left[1-{ }^{14} \mathrm{C}\right]$ alanine (UDP-MurNAc-pentapeptide) was prepared by incubating the UDP-MurNAc-tripeptide with DL- $\left[1-{ }^{14} \mathrm{C}\right]$ alanine $\left(4.5 \mathrm{mCi} \mathrm{mmol}^{-1} ; 166 \mathrm{MBq} \mathrm{mmol}^{-1}\right.$ ) and an extract of sporulating Bacillus sphaericus 9602 (provided by D. J. Tipper) as described by Guinand et al. (1974). This preparation racemizes alanine, synthesizes the dipeptide D-Ala-D-Ala and adds it to the tripeptide in one step.

UDP- $N$-acetylmuramoyl-L-alanyl- $\mu$-D-glutamyl-(L)-meso-2,6-diaminopimelyl-D- $\left[{ }^{14} \mathrm{C}\right]$ alanine (UDP-MurNActetrapeptide) was obtained by excision of the terminal alanine of the pentapeptide derivative using the exocellular D,D-carboxypeptidase of Actinomadura R39 (provided by J.-M. Ghuysen), prepared and purified through the first step as described by Leyh-Bouille et al. (1972). The conditions of incubation and separation of the reaction products by high-voltage electrophoresis have been described (Pellon \& Michel, 1979). The yield was close to $95 \%$ and the specific activity of the UDP-MurNAc-tetrapeptide was $110 \mathrm{~Bq} \mathrm{nmol}^{-1}$.

UDP-MurNAc-L-Ala- $\gamma$-D-Glu-L-lysine was prepared by the method of Strominger et al. (1959) from Staphylococcus aureus incubated with D-cycloserine. The pentapeptide derivative was prepared exactly like the diaminopimelate-containing pentapeptide.

$p$-Nitrophenyl- $N$-acetyl- $\beta$-D-glucosaminide ( $p$-nitrophenyl-2-acetamido-2-deoxy- $\beta$-D-glucopyranoside) was from Sigma. DL- $\left[1-{ }^{14} \mathrm{C}\right]$ Alanine and 2,6 -diamino $\left[1,7-{ }^{14} \mathrm{C}\right]$ pimelic acid were from the Commissariat a 1 'Energie Atomique, Saclay, France; 2,6-diamino[G- $\left.{ }^{3} \mathrm{H}\right]$ pimelic acid dihydrochloride was from Amersham, U.K.

Enzyme assays. $N$-Acetylmuramoyl-L-alanine amidase (MurNAc-L-Ala amidase; EC 3.5.1.28) was assayed as described by van Heijenoort et al. (1975). Endopeptidase was assayed by the method of Tamura et al. (1976) except that the reaction was stopped by boiling for $5 \mathrm{~min}$. The reaction products were located on the chromatogram by counting $0.5 \mathrm{~cm}$ sections of each strip. Activities were expressed as percentage hydrolysis $\mathrm{min}^{-1}$ (mg protein) $)^{-1} \cdot \beta$ - $N$-Acetyl-D-glucosaminidase (EC 3.2.1.30) was assayed by the method of Yem \& Wu (1976). $\mathrm{D}, \mathrm{D}$-Carboxypeptidase and L,D-carboxypeptidase activities were assayed according to Tamura et al. (1976) and transglycosylase was assayed according to Mett et al. (1980); $1 \mathrm{nmol}$ of the diaminopimelate substrate or $0.69 \mathrm{nmol}$ of the lysine substrate was used. $\beta$-D-Galactosidase (EC 3.2.1.23) and alkaline phosphatase (EC 3.1.3.1) were assayed by the methods described by Wallenfels (1962) and Garen \& Levinthal (1960), respectively.

Analytical methods. Murein components were measured as described by Ghuysen et al. (1966); murein cross-linkage was measured by the method of Braun \& Wolff (1975), 3-deoxy-D-manno-octulosonic acid (KDO) by the method of Osborn et al. (1972), and protein by the Lowry method.

Autolysis of washed cells. Bacteria growing exponentially in complete medium with IPTG (Michel et al., 1977) were washed in $0.05 \mathrm{M}$-Tris/maleate buffer $\mathrm{pH} 7.0$ and resuspended in buffers $\mathrm{pH} 6.0$ to $8.4(0.05 \mathrm{M}$ Tris/maleate) or $\mathrm{pH} 8.4$ to $9.4\left(0.05 \mathrm{M}\right.$-glycine/ NaOH). The suspensions were incubated at $37^{\circ} \mathrm{C}$ for $2 \mathrm{~h}$ and the $A_{450}$ and $\beta$-galactosidase activity in the supernatant were determined.

\section{RESULTS AND DISCUSSION}

\section{Autolysis and leakage of cellular components}

In preliminary experiments we observed that the absorbance and viable cell count of envC cultures grown in agitated complete or minimal medium decreased $2 \mathrm{~h}$ after the stationary 
Table 1. Comparison of amounts of cellular components in culture fluids of wild-type $\left(e n v C^{+}\right)$and envC strains of E. coli

The numbers represent the percentage of the total amount (cells plus culture fluid) for each component.

Cell component

Alkaline phosphatase

$\beta$-Galactosidase

5 '-Nucleotidase

Protein

KDO

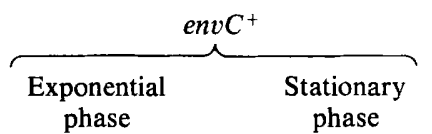

0

1

ND

$1 \cdot 5$

1

9.7

1.6

ND

$1 \cdot 2$

3

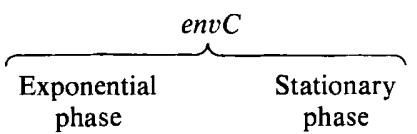

$10 \cdot 8 \quad 38$

$\begin{array}{ll}4 & 14\end{array}$

$29 \quad 75$

$9-11$

$19 \quad 45$

ND, Not determined.

Table 2. Release of $\beta$-galactosidase by non-growing env $C^{+}$and envC strains of $E$. coli

Cells washed in $0.05 \mathrm{M}$-Tris/maleate buffer $\mathrm{pH} 7$ were suspended in $0.05 \mathrm{M}$-Tris/maleate buffer (samples 1 to 6 ) or $0.05 \mathrm{M}$-glycine/ $\mathrm{NaOH}$ buffer (samples 7 to 9 ) and incubated for $120 \mathrm{~min}$ at $37^{\circ} \mathrm{C}$. The $A_{450}$ was then read, the cells were centrifuged and $\beta$-galactosidase activity was measured in the supernatant. $\beta$-Galactosidase activity is expressed in arbitrary units. $\Delta A_{450}$ represents the percentage decrease in absorbance. The initial $A_{450}$ was 0.6 in all the samples.

\begin{tabular}{|c|c|c|c|c|c|}
\hline \multirow{2}{*}{$\begin{array}{c}\text { Sample } \\
\text { no. }\end{array}$} & \multirow[b]{2}{*}{$\mathrm{pH}$} & \multicolumn{2}{|c|}{$e n v C^{+}$} & \multicolumn{2}{|c|}{ enve $C$} \\
\hline & & $\beta$-Galactosidase & $\Delta A_{450}$ & $\beta$-Galactosidase & $\Delta A_{450}$ \\
\hline 1 & 6.0 & 0 & 9 & 33 & 11 \\
\hline 2 & 6.4 & 0 & 10 & 22.5 & 14 \\
\hline 3 & 7.0 & 0 & 10 & 31 & 20 \\
\hline 4 & 7.4 & 0 & 10 & 32 & 20 \\
\hline 5 & 8.0 & 5 & 11 & 35 & 22.5 \\
\hline 6 & 8.4 & 9 & 22 & 51.5 & 35.5 \\
\hline 7 & 8.4 & 0 & 11 & 165 & 29.5 \\
\hline 8 & 9.0 & 0 & $19 \cdot 5$ & 222 & 46.5 \\
\hline 9 & 9.4 & 9 & 26 & 231 & 51 \\
\hline
\end{tabular}

phase was reached. The decrease was about $20 \%$ for the $A_{450}$ and $25 \%$ for the viable count. The parent strain was much more stable under the same conditions, and a slow decrease of both parameters started only after $24 \mathrm{~h}$ incubation. Electron microscopy of stationary-phase envC cells showed a significant proportion of lysed cells. It was reported previously that growing envC cultures release alkaline phosphatase without osmotic shock and it was suggested that the liberation of that periplasmic enzyme was the consequence of leakiness of the outer membrane (Starkova et al., 1978). Thus, it was of interest to determine how much of this alkaline phosphatase release was the result of cell autolysis. The results in Table 1 indicate the amounts of various cell components found in the culture medium of envC and wild-type $\left(e n v C^{+}\right)$bacteria. In exponentially growing cultures, envC lost $10 \%$ of its alkaline phosphatase, about $30 \%$ of its 5 '-nucleotidase and $19 \%$ of its KDO [representing lipopolysaccharide (LPS) from the outer membraneJ. Only $4 \%$ of the $\beta$-galactosidase was found in the medium, indicating indirectly that only a fraction of leaky cells had undergone autolysis. Leakage of periplasmic enzymes is not entirely unexpected in a strain that is abnormally permeable and sensitive to lysozyme without EDTA being present. It should be noted that the percentage of total KDO found in the culture medium of $e n v C$ was greater than that of total $\beta$-galactosidase. This indicates that intact envC cells also shed LPS from the cell envelope. With the exception of total protein, the supernatant of stationary-phase envC cultures contained about three times as much of the released compounds as the supernatant of exponentially growing cultures. Exponentially growing env $C^{+}$cells, on the other hand, 
Table 3. Relative specific activities of murein hydrolases in the soluble and envelope fractions of env $C^{+}$and envC strains of E. coli grown in the presence or absence of $0.58 \mathrm{M}$-sucrose

The values are expressed as a percentage of those obtained with the $e n v C^{+}$strain grown in normal medium.

\begin{tabular}{|c|c|c|c|c|c|}
\hline \multirow[b]{2}{*}{ Enzyme } & \multirow[b]{2}{*}{$\begin{array}{c}\text { Cell } \\
\text { fraction }\end{array}$} & \multicolumn{2}{|c|}{$e n v C^{+}$} & \multicolumn{2}{|c|}{ envC } \\
\hline & & $\begin{array}{l}\text { Normal } \\
\text { medium }\end{array}$ & $\begin{array}{l}\text { Medium } \\
+ \text { sucrose }\end{array}$ & $\begin{array}{l}\text { Normal } \\
\text { medium }\end{array}$ & $\begin{array}{l}\text { Medium } \\
+ \text { sucrose }\end{array}$ \\
\hline$N$-Acetylglucosaminidase & $\begin{array}{l}\text { Soluble } \\
\text { Envelope }\end{array}$ & $\begin{array}{l}100 \\
100\end{array}$ & $\begin{array}{l}157 \\
177\end{array}$ & $\begin{array}{l}187 \\
147\end{array}$ & $\begin{array}{l}177 \\
216\end{array}$ \\
\hline$N$-Acetylmuramoylamidase & Soluble & 100 & 110 & 88 & 116 \\
\hline D,D-Carboxypeptidase $1 \mathrm{~A}+1 \mathrm{~B}^{*}$ & Envelope & 100 & 89 & 128 & 287 \\
\hline D,D-Carboxypeptidase $1 \mathrm{~A}^{\dagger}$ & Envelope & 100 & ND & 138 & 87 \\
\hline L,D-Carboxypeptidase & Envelope & 100 & 100 & 66 & 450 \\
\hline Endopeptidase & $\begin{array}{l}\text { Soluble } \\
\text { Envelope }\end{array}$ & $\begin{array}{l}100 \\
100\end{array}$ & $\begin{array}{l}83 \\
77\end{array}$ & $\begin{array}{r}256 \\
91\end{array}$ & $\begin{array}{l}102 \\
254\end{array}$ \\
\hline Transglycosylase & Envelope & 100 & 166 & 157 & 216 \\
\hline
\end{tabular}

released barely detectable amounts of cellular components. Stationary-phase env $C^{+}$cultures liberated about $10 \%$ of their total alkaline phosphatase but very little of other components.

After being washed, envC cells underwent even more pronounced autolysis. The results in Table 2 show that they released a rather constant amount of $\beta$-galactosidase at $\mathrm{pH}$ values between 6 and 8 . Above pH 8 the breakdown of cell integrity rose steeply. The release of $\beta$-galactosidase roughly corresponded to the degree of loss of absorbance of the cell suspension. The release process was greatly influenced by the buffer constituents. For example, the activity of liberated $\beta$-galactosidase was three times higher in glycine buffer at $\mathrm{pH} 8.4$ than in Tris/maleate buffer of the same $\mathrm{pH}$. No significant enzyme release from wild-type cells was observed at any $\mathrm{pH}$ in glycine or in Tris/maleate buffers.

The supernatant of envC cells incubated as above in $0.05 \mathrm{M}$-Tris/maleate buffer $\mathrm{pH} 8.5$ contained murein-like fragments insoluble in absolute alcohol, but soluble in $66 \%(\mathrm{v} / \mathrm{v})$ ethanol, giving five ninhydrin-positive spots upon chromatography as described by Primosigh et al. (1961). All these spots, upon hydrolysis and chromatography, were shown to contain some or all of the murein components (hexosamine, alanine, glutamic acid) and three of them contained diaminopimelic acid. It seems most likely that they represent murein degradation products. None of these compounds was detected in supernatants of similarly treated wild-type cells (results not shown).

Despite a strong tendency to autolyse, the envC mutant seemed to have a normal rate of murein synthesis as measured by incorporation of labelled diaminopimelic acid during exponential growth. Furthermore, the murein has a normal composition and degree of cross-linkage (D. Karibian, unpublished results).

\section{Murein hydrolase activities in envC cells}

The susceptibility of envC cells to autolysis could imply poorly controlled activity, or abnormal levels, of murein hydrolases. We therefore compared the activities of six of these enzymes in envC and wild-type cells. It was reported earlier that the anomalous division and chain formation of the envC mutant can be phenotypically corrected by adding $0.58 \mathrm{M}$-sucrose to the medium (Starka et al., 1974). Therefore, murein hydrolase activities were measured in extracts of cells grown in the presence or absence of sucrose (Table 3 ). The 
Table 4. Influence of lysophosphatidylethanolamine (LPE), Triton X-100 and sucrose on murein hydrolase activities of env $C^{+}$and envC strains of E. coli

The enzyme activities are expressed as a percentage of those obtained with the env $C^{+}$strain with no addition to the reaction mixture.

\begin{tabular}{|c|c|c|c|c|c|c|c|c|}
\hline \multirow[b]{2}{*}{ Addition } & \multicolumn{2}{|c|}{ L,D-Carboxypeptidase } & \multicolumn{2}{|c|}{ Endopeptidase } & \multicolumn{2}{|c|}{$N$-Acetylglucosaminidase } & \multicolumn{2}{|c|}{ Transgly cosylase } \\
\hline & $e n v C^{+}$ & $e n v C$ & $e n v C^{+}$ & env $\mathrm{C}$ & env $C^{+}$ & envC & $e n v C^{+}$ & enve \\
\hline None & 100 & 80 & 100 & 115 & 100 & 129 & 100 & ND \\
\hline $\mathrm{LPE}^{*}$ & 117 & 102 & 88 & 95 & 103 & 122 & 102 & ND \\
\hline $\begin{array}{l}\text { Triton } \\
\quad \text { X-100 (0.2\%) }\end{array}$ & 96 & 104 & 126 & 140 & 104 & 124 & ND & ND \\
\hline Sucrose $(0.58 \mathrm{M})$ & 100 & 98 & ND & ND & ND & ND & 98 & ND \\
\hline
\end{tabular}

ND, Not determined.

* LPE $(1.8 \mu \mathrm{mol})$ was mixed with extract before adding other solutions, to give final concentrations of $72 \mathrm{~mm}$. $46 \mathrm{~mm}, 5 \mathrm{~mm}$ and $18 \mathrm{~mm}$ in the L,D-carboxypeptidase, endopeptidase, $N$-acetylglucosaminidase and transglycosylase reaction mixtures, respectively.

soluble fraction of envC was richer than that of the wild type in $N$-acetylglucosaminidase and endopeptidase activities. It should be noted that the hydrolysis of $p$-nitrophenylglucosaminide measures only exoglucosaminidase activity, which is not known to be involved directly in autolysis. The transglycosylase activity in the soluble fractions was low in both strains (not shown) and represented only a small fraction of the activity found in the envelopes. The activities of other enzymes did not seem to be markedly different between the strains. The fact that the functions and control of murein hydrolases in vivo are obscure makes it difficult to estimate whether or not differences of $20-50 \%$ are significant. Although Kitano et al. (1980) were able to attribute the autolysis resistance of $\beta$-lactam-tolerant $E$. coli strains to a deficiency in $\mathrm{N}$-acetylmuramidase (transglycosylase) activity, it would be less justifiable to attribute the autolysis sensitivity of the envC strain to any one of the several murein hydrolases that are in excess. Indeed, Yem \& Wu (1976) showed that mutants of $E$. coli with less than $0.2 \%$ of the wild-type level of exo- $\beta$ - $N$-acetylglucosaminidase activity grew and divided normally in rich or minimal media, and their morphology was also normal. On the other hand, MurNAc-L-Ala amidase-deficient and endo- $\beta$ - $N$-acetylglucosaminidase-deficient mutants of Bacillus subtilis formed very long chains of unseparated cells (Fein \& Rogers, 1976).

What is more intriguing is that when envC is grown in medium containing $0.58 \mathrm{M}$-sucrose, a condition that causes the chains of cells to break up into rods, the L,D-carboxypeptidase activity is about sixfold higher than in cells grown without supplementary sucrose (Table 3 ). Beck \& Park (1976) showed that the amount of this enzyme increases just before cell division, suggesting that the L,D-carboxypeptidase might be involved in cell separation. However, the sucrose effect seemed to be on enzyme synthesis rather than on enzyme activity, since the same concentration of sugar added to an enzyme reaction mixture had no effect (Table 4). The D,D-carboxypeptidase activity of sucrose-grown envC was also higher than normal, but the increase was less marked (Table 3).

However, when UDP-MurNAc-pentapeptide containing lysine instead of diaminopimelate was used as the substrate of D,D-carboxypeptidase, the activity in the extract of sucrose-grown envC showed no increase at all. The lysine-containing substrate allows a distinction to be made between the two D,D-carboxypeptidases, 1A and 1B, shown to exist by Tamura et al. (1976), since it is used only by the $1 \mathrm{~A}$ enzyme. Thus, the $1 \mathrm{~A}$ enzyme, which alone was measured with the lysine-containing substrate, is not increased in sucrose-grown $e n v C$. The increased activity observed with the natural substrate was therefore due only to the 1B enzyme. The quantitative interpretation of these results is further complicated by the fact that the product of the reaction is the substrate of L,D-carboxypeptidase, which, being very 
active in these cells, would tend to increase the apparent D,D-carboxypeptidase activity. However, all the activities represent initial catalytic rates and therefore might not be greatly affected by this side-reaction. The latter problem can and will soon be overcome by using substrate labelled only in the terminal alanine (Gorecki et al., 1975).

A recent report from this laboratory showed that the envC membranes contained appreciable levels of lysophosphatidylethanolamine (LPE) as a result of abnormal phospholipase A activity (Michel \& Starka, 1979). Since lysophospholipids and synthetic detergents have been shown to influence many membrane-associated enzymes (Rothfield \& Romeo, 1971), it was of interest to test the effect of LPE on murein hydrolase activities. The results in Table 4 show that LPE as well as the non-ionic detergent Triton X-100 did not significantly influence the activities tested. Therefore, if the fragility of envC cells is due to the presence of lysophospholipid in the envelope, the primary effect is probably not on murein hydrolase activities.

The correlation between cell wall growth, septum formation and murein hydrolase activities remains unclear. For instance, it was reported recently that the mutants of $E$. coli deficient in D,D-carboxypeptidase 1A (dacA) or in D,D-carboxypeptidase 1B (dacB) grow and synthesize murein normally (Matsuhashi et al., 1978). This would mean that these two murein hydrolases do not participate either in murein synthesis or in septum splitting. This latter function was attributed by Wolf-Watz \& Normark (1976) to the MurNAc-L-Ala amidase. Their conclusion was based on the fact that the envA chain-forming mutant had a sixfold lower amidase activity than the parent $E$. coli D21. However, the present results show that in spite of its chain-forming phenotype, envC has the same amidase activity as the parent and that this activity does not change in env $C$ cells grown in the presence of $0.58 \mathrm{M}$-sucrose, a condition under which they divide at the same rate as the parent strain. On the other hand, L,D-carboxypeptidase, which was lower in envC than in the wild type, increased considerably when the mutant was grown in the presence of hypertonic sucrose. This suggests that L,D-carboxypeptidase is involved in septum splitting, but the problem merits further investigation.

It is most probable that the murein hydrolase activities measured in disrupted cells do not correspond to the actual activities needed for normal growth and division. In the case of env $C$, its autolytic behaviour can hardly be explained by the observed increases in endopeptidase and $\mathrm{N}$-acetylglucosaminidase activities in cell fractions. In the light of these considerations, it seems probable that the triggering of autolysis in $E$. coli depends rather on the state and conditions of other envelope constituents than on the activity of murein hydrolases. Previous results from this laboratory showing important alterations of the envC outer membrane are not inconsistent with this view.

This work was supported by grant 78.1.100.1 from the Institut National de la Santé et de la Recherche Médicale and grant A.I. 030093 from the Centre National de la Recherche Scientifique. We wish to thank J. van Heijenoort and his group for their assistance with the assays of $\mathrm{N}$-acetylmuramoyl-L-alanine amidase.

\section{REFERENCES}

BECK, B. D. \& PARK, J. T. (1976). Activity of three murein hydrolases during the cell division cycle of Escherichia coli $\mathrm{K}-12$ as measured in toluene-treated cells. Journal of Bacteriology 126, 1250-1260.

Braun, V. \& WolfF, H. (1975). Attachment of lipoprotein to murein (peptidoglycan) of Escherichia coli in the presence and absence of penicillin FL 1060. Journal of Bacteriology 123, 888-897.

FAN, D. P. (1970). Autolysin(s) of Bacillus subtilis as dechaining enzyme. Journal of Bacteriology 103, 494-499.

FeIN, J. E. \& Rogers, H. J. (1976). Autolytic enzyme-deficient mutants of Bacillus subtilis 168. Journal of Bacteriology 127, 1427-1442.

Garen, A. \& Levinthal, C. (1960). A fine-structure genetic and chemical study of the enzyme alkaline phosphatase of $E$. coli. I. Purification and characterization of alkaline phosphatase. Biochimica et biophysica acta 38, 470-483.

Ghuysen, J.-M. \& Shockman, G. D. (1973). Biosynthesis of peptidoglycan. In Bacterial Membranes and Walls, pp. 37-130. Edited by L. Leive. New York: M. Dekker.

Ghuysen, J.-M., TIPPER, D. J. \& Strominger, J. L. 
(1966). Enzymes that degrade bacterial cell walls. Methods in Enzymology 8, 685-699.

Gorecki, M., BAR-El, A., Burstein, Y., Patchornik, Y. \& Chain, A. B. (1975). The purification of D-alanine carboxypeptidase from Escherichia coli B on a penicillin-Sepharose column. Biochemical Journal 147, 131-137.

Guinand, M., Michel, G. \& TiPPER, D. J. (1974). Appearance of a $\gamma$-D-glutamyl(L)mesodiaminopimelate peptidoglycan hydrolase during sporulation in Bacillus sphaericus. Journal of Bacteriology 120, 173-184.

HARTMANN, R. (1973). Isolierung und Charakterisierung einer penicillinempfindlichen Murein-Endopeptidase aus der Zellwand von E. coli. Dissertation, University of Tübingen, Germany.

Hartmann, R., Bock-Hennig, S. B. \& Schwarz, U. (1974). Murein hydrolases in the envelope of Escherichia coli. European Journal of Biochemistry 41, 203-208.

Hinks, R. P., Daneo-Moore, L. \& Shockman, G. D. $(1978 a)$. Cellular autolytic activity in synchronized populations of Streptococcus faecium. Journal of Bacteriology 133, 822-829.

Hinks, R. P., Daneo-Moore, L. \& Shockman, G. D. $(1978 b)$. Relationship between cellular autolytic activity, peptidoglycan synthesis, septation, and the cell cycle in synchronized populations of Streptococcus faecium. Journal of Bacteriology 134, 10741080.

Kitano, K., Williamson, R. \& Tomasz, A. (1980). Murein hydrolase defect in the $\beta$-lactam tolerant mutants of Escherichia coli. FEMS Microbiology Letters 7, 133-136.

Leduc, M. \& VAN Helenoort, J. (1980). Autoly sis of Escherichia coli. Journal of Bacteriology 142, 52-59.

Leyh-Bouille, M., NAKel, M., Frère, J.-M., Johnson, K., GhuYSEN, J.-M., NiETo, M. \& Perkins, H. R. (1972). Penicillin-sensitive DDcarboxypeptidases from Streptomyces strains R39 and K11. Biochemistry 11, 1290-1298.

Lugtenberg, E. J. J., DE HAAS-Menger, L. \& RUYTERS, W. H. M. (1972). Murein synthesis and identification of cell wall precursors of temperaturesensitive lysis mutants of Escherichia coli. Journal of Bacteriology 109, 326-335.

Matsuhashi, M., Maruyama, I. N., Takagaki, Y., TAMAKI, S., Nishimura, Y. \& Hirota, Y. (1978). Isolation of a mutant of Escherichia coli lacking penicillin-sensitive D-alanine carboxypeptidase IA. Proceedings of the National Academy of Sciences of the United States of America 75, 2631-2635.

MetT, H., Keck, W., Funk, A. \& Schwarz, U. (1980). Two different species of murein transglycosylase in Escherichia coli. Journal of Bacteriology 144, 45-52.

Michel, G. \& Starka, J. (1979). Phospholipase A activity with integrated phospholipid vesicles in intact cells of an envelope mutant of Escherichia coli. FEBS Letters 108, 261-265.

Michel, G., Di Savino, D. \& Starka, J. (1977).
Phospholipid composition and phenotypic correction of an envC division mutant of Escherichia coli. Journal of Bacteriology 129, 145-150.

Mitchell, P. \& MoYle, J. (1956). Autolytic 'protoplast' release in Bacterium coli. Nature, London 178, 993.

Osborn, M. J., GAnder, J. E., Parisi, E. \& Carson, J. (1972). Mechanism of assembly of the outer membrane of Salmonella typhimurium. Journal of Biological Chemistry 247, 3262-3272.

PelloN, G. \& Michel, G. (1979). Identification d'une nucléotide pyrophosphatase exocellulaire dans le milieu de culture de Streptomyces mediterranei ME/R17. Canadian Journal of Microbiology 25, 53-60.

Primosigh, J., Pelzer, H., MaAs, D. \& Weidel, W. (1961). Chemical characterization of mucopeptides released from the $E$. coli B cell wall by enzymic action. Biochimica et biophysica acta 46, 68-80.

Rodolakis, A., Thomas, P. \& STARKa, J. (1973). Morphological mutants of Escherichia coli. Isolation and ultrastructure of a chain-forming envC mutant. Journal of General Microbiology 75, 409416.

RothFIELD, L. \& RoMEo, D. (1971). Enzyme reactions in biological membranes. In Structure and Function of Biological Membranes, pp. 251-284. Edited by L. I. Rothfield. New York: Academic Press.

Starka, J., Di Savino, D., Michel, G., Rodolakis, A. \& Thomas, P. (1974). Phenotypic expression of an envC division mutant of Escherichia coli. Annales de Microbiologie 125B, 227-232.

Starkova, Z., Thomas, P. \& Starka, J. (1978). Morphological mutants of Escherichia coli. Nature of the permeability barrier in mon and envC cells. Annales de Microbiologie 129A, 265-284.

Strominger, J. L., ThrenN, R. H. \& Scott, S. S. (1959). Oxamycin, a competitive antagonist of the incorporation of $\mathrm{D}$-alanine into a uridine nucleotide in Staphylococcus aureus. Journal of the American Chemical Society 81, 3803-3804.

TAmura, T., ImaE, Y. \& Strominger, J. L. (1976). Purification to homogeneity and properties of two D-alanine carboxypeptidases I from Escherichia coli. Journal of Biological Chemistry 251, 414-423.

van Heijenoort, J., Parquet, C., Flouret, B. \& van Heijenoort, Y. (1975). Envelope-bound $N$-acetylmuramyl-L-alanine amidase of Escherichia coli K 12. Purification and properties of the enzyme. European Journal of Biochemistry 58, 611-619.

WALLENFELS, K. (1962). $\beta$-Galactosidase. Methods in Enzymology 5, 212-219.

WOLF-WATZ, H. \& Normark, S. (1976). Evidence for a role of $N$-acetylmuramyl-L-alanine amidase in septum separation in Escherichia coli. Journal of Bacteriology 128, 580-586.

YEM, D. W. \& WU, H. C. (1976). Isolation of Escherichia coli $\mathrm{K}-12$ mutants with altered levels of $\beta-N$-acetylglucosaminidase. Journal of Bacteriology 125, 372-373. 